\title{
Prosthodontic and Periodontal Status and Needs in a Selected Population of Urban Poor in the Philippines: A Pilot Study
}

Vincent Torresyap, Jay Hoover, Maria Torresyap, Chandima Karunanayake

\begin{abstract}
Purpose: To determine the prosthodontic and periodontal status and needs in a group of adults from a poor urban community in the Philippines.
\end{abstract}

Materials and methods: A sample consisting of 401 poor urban adults in a district in the Philippines was assessed using the WHO oral health assessment form. The examinations were conducted in natural light with a mouth mirror, community periodontal index (CPI) probe and an explorer with the subject seated in a regular chair. The following prosthodontics/ malocclusion traits were assessed; presence or absence of fixed and or removable appliances, treatment needs, presence of spacing, crowding in the incisal segments, overjet, open bite and posterior cross bite. The periodontal condition was assessed by means of the community periodontal index of treatment needs (CPITN) in relation to selected index teeth: The statistical analysis was carried out using statistical package for the social sciences (SPSS) (version 21.0). One-way ANOVA was used to compare the means and chi-square and Fisher's exact test was used to compare the proportions. The significance level was set at $\alpha=0.05$.

Results: The majority of adult Filipinos had either calculus $(84.8 \%)$ or shallow probing depths $(11 \%)$. Only $1.7 \%$ had probing depths equal to or greater than $6 \mathrm{~mm}$. Forty four (10.9\%) subjects were wearing complete dentures in the maxilla and mandible and $11.7 \%$ had removable partial dentures in the maxilla while only $1.2 \%$ was wearing partials in the mandible. There was no statistically significant difference between the genders with regard to prosthetic status. Overall, 70.3 and $88.5 \%$ required prosthesis in the maxilla and mandible respectively. However, more subjects needed full prosthesis in the maxilla $(25.9 \%)$ compared to mandible $(16.5 \%)$.

Conclusion: The majority of the sampled Filipino adults had significant unmet periodontal (high calculus rates and gingivitis) and prosthodontics needs.

Keywords: Philippines, Prosthodontic, Periodontal, Status, Needs, Adults.

How to cite this article: Torresyap V, Hoover J, Torresyap M, Karunanayake C. Prosthodontic and Periodontal Status and Needs in a Selected Population of Urban Poor in the Philippines: A Pilot Study. Int J Prosthodont Restor Dent 2013;3(4):136-142.

\section{Source of support: Nil}

Conflict of interest: None

\section{INTRODUCTION}

The prevalence of caries, periodontal diseases and edentulism is still considered to be moderate to high in many parts of the developing world and is more pronounced in underprivileged population groups in these nations. ${ }^{1}$ Large segments of the population in developing nations consist of rural dwellers and the urban poor. It is well-established that there are discrepancies in health including oral health between the urban rich and the urban poor especially in these countries. ${ }^{2}$ According to a report published by the World Bank, 'the urban poor are particularly vulnerable in times of crisis due to their heavy reliance on a cash economy, job losses and wage reductions in urban-based industries, and no agricultural production to fall back on' ${ }^{3}$ Although the definition of urban poverty is not well-defined, the National Statistical coordination Board of the Republic of the Philippines, describes the urban poor as an individual residing in an urban area whose income falls below the official poverty threshold. ${ }^{4}$ In 2009 , the annual per capita poverty threshold in the Philippines was PhP 16841, about US\$ 385 per year. ${ }^{5}$

A significant proportion of adults living in developing nations are continuing to lose teeth likely due to untreated caries and periodontal diseases and probably remain partially or totally edentulous. Loss of teeth may affect the oral health related quality of life and cause difficulties in chewing, leading to possible malnutrition. ${ }^{6-8}$ Tooth loss also appears to impact self-confidence, restrict social activities and interpersonal relationships. ${ }^{9,10}$

In addition to being one of the major contributors to tooth loss, several epidemiological observational studies indicate an association between periodontal disease and systemic disorders such as atherosclerotic vascular disease, pre-term low birth weight infants, pulmonary disease and diabetes. Although possibly due to a lack of long-term studies, there is little evidence to demonstrate either causality or treatment effect. $^{11}$

Unfortunately, oral health is usually not considered a priority issue by the public health sector in developing countries, particularly among disadvantaged groups such as the urban poor. When a low significance is accorded to oral diseases by the public health sector, combined by factors such as economic barriers, low utilization of existing oral health services and a scarcity of preventive oral health programs, caries and periodontal disease ensue, resulting in pain and tooth loss. ${ }^{12}$ IBON Foundation, Inc., an independent development institution established in 1978, 
reported in a recent survey that approximately just over 68\% of the population in the Philippines, considered themselves as poor. ${ }^{13}$

The prevalence of oral diseases continues to be a public health issue in the Philippines. According to data published by the Department of Health, Republic of the Philippines, it is estimated that more than $75 \%$ of the adult population has some form of periodontal disease ${ }^{14}$ and $82 \%$ of 12 -year-old children had caries (mean DMFT 2.9) ${ }^{15}$ However, besides data from a few national surveys, there is a dearth of published information concerning the oral health of adult Filipinos especially in those considered the urban poor or poor. Therefore, the purpose of the present investigation was to gather baseline data concerning the prosthodontic and periodontal status and needs in a group of adult Filipinos residing in a poor urban community in the City of San Jose, located in the province of Batangas, Philippines.

\section{MATERIALS AND METHODS}

San Jose is situated in the province of Batangas, Philippines about $85 \mathrm{~km}$ from the capital city of Manila. According to the 2010 census, ${ }^{16}$ San Jose had a population of 68,517 people living in approximately 10,000 households.

The subjects for the present study were selected using convenience sampling from among adults recruited from Barangay Banay-Banay, a poor district in the city and one of thirty three urbanized Barangays comprising the City of San Jose. A Barangay is a term that could refer to an administrative unit, district, village, ward, suburb or inner city neighborhood. Banay Banay is approximately $4 \mathrm{~km}$ from the city proper of San Jose, with the population of approximately 6300 according to the most recent census. ${ }^{16}$ The reasons for obtaining a convenience sample were mainly due to budgetary and time constraints and the need to establish some form of baseline data in this population group. The study was conducted in full accordance with ethical principles and with the approval of the Behavioral Research Ethics Board, University of Saskatchewan, Canada.

Sample size calculations reveled that a minimum of 288 persons within the community needed to be assessed in order to detect a 6 to $10 \%$ increase in the prevalence of dental caries and periodontal diseases compared to the general population at $\alpha=0.05$ (type I error) with power of $80 \% .^{17,18}$ To reduce the margin of error further, it was decided to obtain a sample size of approximately 400 adults aged 16 years and older who were recruited by going door to door and requesting participation till the target size was reached.

The subjects were examined by three calibrated dentists, VT, JH, WT, aided by three recording assistants using the WHO oral health assessment form. ${ }^{19}$ The following were assessed; prosthodontic status and needs by one examiner Vincent Torresyap (VT), the Community Periodontal Index of Treatment Needs (CPITN), fluorosis, oral mucosal lesions by Jay Hoover $(\mathrm{JH})$, and dentition status by Maria Torresyap (MT). The results of the analysis of data pertaining to oral mucosal lesions, fluorosis, dentition status and treatment needs will be reported separately. In addition, a questionnaire was administered to the subjects prior to the oral examination, to identify oral hygiene practices, attitudes, knowledge and barriers to oral care. The results of this survey will be described once data analysis is completed. A signed consent was obtained prior to the examination and a copy provided to each subject. It was assumed that some subjects could be illiterate in the English language and hence, the consent form outlining the nature of the study and the questionnaire were written in both the official languages of the Philippines, Tagalog and English. A signed consent was obtained from each subject prior to the study and a copy provided to each participant. In addition, local multilingual translators with a Southern Tagalog dialect guided each participant through the questionnaire and the consent.

The intraoral examinations were conducted in a rented facility, in natural light and using a mouth mirror, a Community Periodontal Index (CPI) probe and an explorer with the subject seated in a regular chair. A battery operated head lamp was used as an added source of illumination. The following prosthodontics/malocclusion traits were assessed; presence or absence of fixed and or removable appliances, treatment needs, presence of spacing, crowding in the incisal segments, overjet, open bite, anterior posterior relationships and posterior cross bite. Anterior maxillary overjet was measured with the teeth in centric occlusion and measured from the labial-incisal edge of the upper incisor to the labial surface of the corresponding lower incisor. The periodontal condition was assessed by means of the CPITN to include the presence of gingival bleeding on gentle probing the sulcus or pocket, calculus and probing depths: $4-5 \mathrm{~mm}$ and $\geq 6 \mathrm{~mm}$ in relation to the following index teeth: $17,16,11,26,27$, $37,36,31,46,47$.

Intra-rater reliability was assessed with the intra-class correlation coefficient (ICC) prior to the survey. Using the sample size determination approach described by Shrout and Fleiss, ${ }^{20}$ eight adult subjects were selected at random to achieve $80 \%$ power with agreement of 0.8 intraexaminer variability and two repeated measures. The results of the intra class correlation were $0.951,0.926$ and 0.925 for the three examiners.

The statistical analysis was carried out using Statistical Package for the Social Sciences (SPSS) software (version 21.0). One-way ANOVA was used to compare the means 
and chi-square and Fisher's exact test was used to compare the proportions. The significance level was set at $\alpha=0.05$.

\section{RESULTS}

The sample size of 401 adults consisted predominantly of females (337 or $84 \%$ ) compared to males (64 or $16 \%$ ). The mean age (SD) was 41.4 years (15.2) with a maximum of 85 and a minimum of 16 years.

The CPITN was recorded in 355 subjects. Forty six subjects were excluded as they did not have the selected teeth. The number and percentage of subjects as per the CPITN codes and for selected variables are shown in Tables 1 and 2 respectively. The overall CPI score of the participant represented the value of the highest recorded score for that individual. The majority of adult Filipinos in the selected sample had either calculus $(84.8 \%)$ or shallow probing depths (11\%). Only $1.7 \%$ had probing depths equal to or greater than $6 \mathrm{~mm}$ (Table 1). Age, gender, self-reported current smoking status, and frequency of tooth brushing did not show statistically significant difference with CPI codes (Table 2). The mean number of sextants affected by calculus was by far, higher than sextants affected by bleeding only and shallow or deep pockets (Table 3 ).

Table 4 illustrates the mean number of CPI sextants in the three age groups. There were no differences in the age groups with regard to shallow and deep pockets; however, there was significantly greater number of sextants with

\begin{tabular}{llllll}
\multicolumn{6}{c}{ Table 1: Number and percentage of subjects as per the CPI } \\
codes $(\mathrm{n}=355)$
\end{tabular}

calculus in those less than 30 years of age compared to those over the age of 50 .

The prosthodontics status, needs, occlusal relationships including the presence of spacing, crowding, maxillary and mandibular overjet, open bite, posterior cross bite and anterior-posterior relationships were assessed in all subjects. The majority of subjects had removable partial dentures in the maxilla (11.7\%) while only $1.2 \%$ was wearing partials in the mandible. Forty four (10.9\%) subjects were wearing complete dentures in the maxilla and mandible. There was no statistically significant difference between the genders with regard to prosthetic status (Table 5). The prosthetic treatment needs in the subjects (Table 6) revealed that in total, $70.3 \%$ (282) and $88.5 \%$ (355) required some type of prosthesis in the maxilla and mandible respectively. However, more subjects needed full prosthesis in the maxilla (25.9\%) compared to mandible (16.5\%). The frequency of occlusal relationships is depicted in Table 7 . Nearly $62 \%$ of subjects had a maxillary overjet with a mean of $1.85 \mathrm{~mm}$ Overjet was not recorded in 127 subjects either due to an absence of anterior teeth or an edge to edge bite.

The presence of a posterior cross bite was observed in $11.2 \%$ of the subjects. However, the presence or absence of this anomaly was not recorded in nearly $28 \%$ of the study population either as a result of the absence of the upper or lower posterior teeth or the presence of a posterior open bite. In addition, approximately $45 \%$ of the subjects exhibited crowding in the anterior segments and $20 \%$, spacing in these segments.

\section{DISCUSSION}

This study was carried out in a relatively poor district in the City of San Jose, Batangas, Philippines, to assess the prevalence of oral conditions and treatment needs among a

\begin{tabular}{|c|c|c|c|c|c|c|c|}
\hline & Variable & $\begin{array}{l}\text { Healthy } \\
\text { (code 0) }\end{array}$ & $\begin{array}{l}\text { Bleeding } \\
\text { (code 1) }\end{array}$ & $\begin{array}{l}\text { Calculus } \\
\text { (code 2) }\end{array}$ & $\begin{array}{l}\text { Shallow } \\
\text { pockets } \\
\text { (code 3) }\end{array}$ & $\begin{array}{l}\text { Deep } \\
\text { pockets } \\
\text { (code 4) }\end{array}$ & $\begin{array}{l}\text { Chi-square exact test } \\
(p \text {-value })^{\#}\end{array}$ \\
\hline \multirow[t]{3}{*}{ Age (years) } & $<30$ & 2 & 2 & 84 & 11 & 1 & $10.41(p=0.226)$ \\
\hline & $30-49$ & 2 & 1 & 150 & 21 & 1 & \\
\hline & $\geq 50$ & 2 & 0 & 67 & 7 & 4 & \\
\hline \multirow[t]{2}{*}{ Gender } & Male & 0 & 1 & 46 & 8 & 1 & $2.537(p=0.643)$ \\
\hline & Female & 6 & 2 & 255 & 31 & 5 & \\
\hline \multirow{2}{*}{$\begin{array}{l}\text { Current smoking } \\
\text { status }\end{array}$} & Yes & 0 & 1 & 50 & 6 & 1 & $1.369(p=0.913)$ \\
\hline & No & 4 & 2 & 216 & 25 & 5 & \\
\hline \multirow[t]{4}{*}{$\begin{array}{l}\text { Frequency of tooth } \\
\text { brushing }\end{array}$} & $\begin{array}{l}\text { Once a week/ } \\
\text { occasionally }\end{array}$ & 0 & 0 & 6 & 0 & 0 & \\
\hline & Once/day & 2 & 0 & 26 & 10 & 0 & $15.937(p=0.204)$ \\
\hline & Twice/day & 4 & 3 & 261 & 28 & 6 & \\
\hline & Thrice/day & 0 & 0 & 2 & 0 & 0 & \\
\hline
\end{tabular}

${ }^{\# p}$-values are from Fisher's exact test 
Prosthodontic and Periodontal Status and Needs in a Selected Population of Urban Poor in the Philippines: A Pilot Study

\begin{tabular}{llllll}
\hline \multicolumn{2}{c}{ Table 3: Mean number and standard deviation (SD) of sextants affected by periodontal conditions } \\
\hline & Healthy (code 0) & Bleeding (code 1) & Calculus (code 2) & $\begin{array}{l}\text { Shallow pockets } \\
\text { (code 3) }\end{array}$ & $\begin{array}{l}\text { Deep pockets } \\
\text { (code 4) }\end{array}$ \\
\hline Mean & 0.54 & 0.25 & 2.95 & 0.13 & 0.08 \\
SD & 1.06 & 0.66 & 1.94 & 0.42 & 0.15 \\
\hline
\end{tabular}

\begin{tabular}{lcclll} 
& Table 4: Mean number (SD) of sextants affected by periodontal conditions in various age groups \\
\hline Age group & Healthy (code 0)* & Bleeding (code 1) ${ }^{* *}$ & Calculus (code 2)*** & $\begin{array}{l}\text { Shallow pockets } \\
\text { (code 3) }\end{array}$ & $\begin{array}{l}\text { Deep pockets } \\
\text { (code 4) })^{\# \#}\end{array}$ \\
\hline$<30$ & $1.13(1.37)$ & $0.65(1.01)$ & $3.57(1.80)$ & $0.13(0.37)$ & $0.01(0.10)$ \\
$30-49$ & $0.49(0.98)$ & $0.16(0.49)$ & $3.34(1.76)$ & $0.16(0.50)$ & $0.01(0.15)$ \\
$\geq 50$ & $0.11(0.48)$ & $0.04(0.24)$ & $1.80(1.86)$ & $0.08(0.32)$ & $0.03(0.18)$ \\
\hline
\end{tabular}

ANOVA: $F^{*}=29.26, p<0.0001 ; F^{* *}=29.62, p<0.0001 ; F^{* * *}=34.12, p<0.0001 ; F^{\#}=1.552, p=0.213 ; F^{\# \#}=1.02, p=0.362$

\begin{tabular}{|c|c|c|c|c|c|c|}
\hline \multirow[t]{2}{*}{ Prosthesis present } & \multicolumn{3}{|c|}{ Prosthetic status maxilla } & \multicolumn{3}{|c|}{ Prosthetic status mandible } \\
\hline & Female & Male & Total & Female & Male & Total \\
\hline No & $266(66.3)$ & $57(14.2)$ & $323(80.5)$ & $315(78.6)$ & $63(15.7)$ & $378(94.3)$ \\
\hline \multirow[t]{2}{*}{ Yes } & $71(17.8)$ & $7(1.7)$ & $78(19.5)$ & $22(5.5)$ & $1(0.2)$ & $23(5.7)$ \\
\hline & \multicolumn{3}{|c|}{$p$-value $=0.083$} & \multicolumn{3}{|c|}{$p$-value $=0.148$} \\
\hline \multicolumn{7}{|l|}{ Type of prosthesis } \\
\hline Bridge & $2(0.5)$ & $0(0.0)$ & $2(0.5)$ & $3(0.7)$ & $0(0.0)$ & $3(0.7)$ \\
\hline $\begin{array}{l}\text { More than one } \\
\text { bridge }\end{array}$ & $0(0.0)$ & $0(0.0)$ & $0(0.0)$ & $0(0.0)$ & $0(0.0)$ & $0(0.0)$ \\
\hline $\begin{array}{l}\text { Partial denture } \\
\text { and/or multi-unit } \\
\text { prostheses }\end{array}$ & $42(10.2)$ & $5(1.2)$ & $47(11.7)$ & $0(0.0)$ & $5(1.2)$ & $5(1.2)$ \\
\hline Both bridge(s) & $0(0.0)$ & $0(0.0)$ & $0(0.0)$ & $0(0.0)$ & $0(0.0)$ & $0(0.0)$ \\
\hline $\begin{array}{l}\text { Full removable } \\
\text { denture }\end{array}$ & $27(6.7)$ & $2(0.5)$ & $29(7.2)$ & $14(3.5)$ & $1(0.2)$ & $15(3.7)$ \\
\hline
\end{tabular}

\#䙵-values are from Fisher's exact test

\begin{tabular}{|c|c|c|c|c|c|c|}
\hline & & ble 6: Pros & eeds accorc & ender $(n=4$ & & \\
\hline Prosthesis need & & sthetic sta & silla & & sthetic statc & dible \\
\hline & Female & Male & Total & Female & Male & Total \\
\hline No & $102(25.5)$ & $17(4.2)$ & $119(29.7)$ & $38(9.5)$ & $8(2.0)$ & $46(11.5)$ \\
\hline Yes & $235(58.6)$ & $47(11.7)$ & $282(70.3)$ & $299(74.6)$ & $56(14.0)$ & $355(88.5)$ \\
\hline & & $p$-value $=$ & & & $p$-value $=$ & \\
\hline Type of prosthesis $r$ & eded & & & & & \\
\hline $\begin{array}{l}\text { Need for one-unit } \\
\text { prosthesis }\end{array}$ & $146(36.4)$ & $29(7.2)$ & $175(43.6)$ & $240(59.8)$ & $42(10.5)$ & $282(70.3)$ \\
\hline $\begin{array}{l}\text { Need for multi-unit } \\
\text { prostheses }\end{array}$ & $0(0.0)$ & $0(0.0)$ & $0(0.0)$ & $2(0.5)$ & $0(0.0)$ & $2(0.5)$ \\
\hline $\begin{array}{l}\text { Need for a } \\
\text { combination of one }\end{array}$ & $0(0.0)$ & $0(0.0)$ & $0(0.0)$ & $1(0.2)$ & $0(0.0)$ & $1(0.2)$ \\
\hline $\begin{array}{l}\text { Need for full } \\
\text { prosthesis }\end{array}$ & $86(21.4)$ & $18(4.5)$ & $104(25.9)$ & $52(13.0)$ & $14(3.5)$ & $66(16.5)$ \\
\hline $\begin{array}{l}\text { Only needs repair/ } \\
\text { reline }\end{array}$ & $3(0.7)$ & $0(0.0)$ & $3(0.7)$ & $4(1.0)$ & $0(0.0)$ & $4(1.0)$ \\
\hline
\end{tabular}

${ }^{\# p}$-values are from Fisher's exact test

group of adults. To the best of our knowledge this is probably the first oral health survey in recent years, among the urban poor adults in the Philippines. A study completed in 1986 by Garcia and Cutress ${ }^{21}$ assessed only the periodontal treatment needs in 2400 dentate adults aged 15 to 65 years. The present sample comprised of predominantly females which was not surprising considering the fact that the study was conducted during the week days when most men would be out working. The periodontal conditions were assessed using the CPITN, which, when used alone to assess the periodontal status may not be the most reliable tool as for example, it does not directly measure tissue loss. ${ }^{22}$ However, 


\begin{tabular}{lll}
\multicolumn{3}{c}{ Table 7: Frequency of occlusal relationships } \\
\hline Occlusion & $\begin{array}{c}\text { Frequency } \\
n(\%)\end{array}$ & $\begin{array}{l}\text { Mean } \pm \text { SD; } \\
\text { Range in } m m\end{array}$ \\
\hline Overjet & & \\
No overjet & $19(4.7)$ & $\pm 1.85 ;(0.5-15)$ \\
Max. overjet & $247(61.6)$ & $1.69 \pm 0.96 ;(0.5-3)$ \\
Mand. overjet & $8(2.0)$ & \\
Not recorded & $127(31.7)$ & \\
Open bite & & \\
Yes & $8(2.0)$ & \\
No & $393(98.0)$ & \\
Ant-post. relationship & & \\
Normal & $58(14.5)$ & \\
Half cusp & $165(41.1)$ & \\
Full cusp & $59(14.7)$ & \\
Not recorded & $119(29.7)$ & \\
Post. cross bite & & \\
Present & $45(11.2)$ & \\
Absent & $245(61.1)$ & \\
Not recorded & $111(27.7)$ & \\
\hline
\end{tabular}

the index is simple and quick to use, reproducible and has been used in numerous countries around the globe as a means of increasing uniformity in periodontal epidemiology. ${ }^{23}$ Only $1.7 \%$ of the dentate subjects having at least one sextant with the selected teeth had healthy periodontium while dental calculus was the predominant finding followed by shallow probing depths. Similar findings with significantly greater number of codes of either 2 (calculus) or 3 (shallow pocketing) have been reported in the 1986 national survey of adult Filipinos, ${ }^{21}$ middle aged populations in Iran ${ }^{24}$ rural populations in Haryana, India ${ }^{25}$ and in Libya ${ }^{26}$ Probing depths equal or greater than $6 \mathrm{~mm}$ was not a significant finding in the above studies or in the present study. It is possible that the presence of large deposits of supragingival and subgingival calculus may have hindered accurate probing of the sulcus. Interestingly, self-reported current smoking status, and frequency of tooth brushing did not show statistically significant differences with CPI codes.

The present study used one of the following criteria to assess prosthetic needs; completely edentulous, severe malocclusion, nonrestorable caries and grade 3 tooth mobility.

Previous studies concerning prosthetic status and needs have focused on the older adult in hospitals or institutions whereas the present study comprised mostly of middle aged adults belonging to a poorer socioeconomic group. ${ }^{27-30}$ Fixed prosthesis was an uncommon finding while only $10.9 \%$ of the adult Filipinos were wearing full removable dentures despite the fact that $42.4 \%$ required full prosthesis. The reason for this could be financial due to the fact that the sample was drawn from a predominantly poor area and many may not be able to afford adequate dental insurance. Similar findings were reported in a group of adults aged

20 to 74 in rural India. ${ }^{25}$ However, Kumar et a ${ }^{31}$ assessing the needs of laborers aged 15 to 54 years also from India found that no subject was in need of a complete denture. Only $15.5 \%$ of these Indian laborers were in need of partial prosthesis probably due to the fact that the mean age of the sample was less than that of the present study. There were 370 (92.3\%) Filipino adults (mean age 41.4 years) who required a prosthetic devise in one or both jaws which is similar to the findings of Ettinger and Beck ${ }^{32}$ who reported a prevalence of $81 \%$ in normative prosthetic needs in a group of Germans. The number of adult Filipinos wearing a removable prosthetic appliance in the maxilla was higher $(19.5 \%)$ than in the mandible (5.7\%) however, more subjects needed an appliance in the mandible (88.5) compared to the maxilla $(70.3 \%)$. Similar findings have been reported elsewhere. ${ }^{24}$

Malocclusion, a commonly observed dental condition, is described as an anomaly of the teeth and or an irregular arrangement of the arches that is outside the ideal range. The association between malocclusion and periodontal diseases, temporomandibular disorders, disturbances in chewing, swallowing, speech and psychological issues related to impaired orofacial esthetics is well-established. ${ }^{33-36}$

The most common malocclusion trait was anterior crowding which was noted in nearly half of the population of adult Filipinos while the least common traits among adults with both upper and lower molar teeth was posterior cross bite and open bite. Similar results were observed in a recent study among a group of adults and children with special needs in India. ${ }^{37}$ Approximately $62 \%$ of the present sample had a mean maxillary anterior overjet of $1.68 \mathrm{~mm}$ which is just below the normal range of 2 to $3 \mathrm{~mm}$ according to Profit and Fields. ${ }^{34}$ The clinical significance of this finding is unknown. The limitations of this study included the significantly higher percentage of female subjects and the method of sampling.

Based on the findings of the present study and considering the economics of the country, it is unlikely that traditional approaches to prevent and treat oral diseases in the context of limited resources will succeed in addressing the unmet prosthodontic and periodontal needs of the population. It is strongly suggested that the local government and dental nongovernmental organizations consider applying and integrating inexpensive, feasible and sustainable treatment modalities, such as the WHO's basic package of oral care which includes oral urgent treatment (OUT), affordable fluoride toothpastes (AFT) and atraumatic restorative treatment (ART). ${ }^{38,39}$ Further studies using randomized sampling in other locales should be undertaken to determine if similar needs exists in the Philippines with regards to periodontal diseases and prosthodontics. 


\section{CONCLUSION}

The results of this study demonstrates that the majority of Filipino adults living in a poorer district within the City of San Jose, Batangas, Philippines have significant unmet periodontal (high calculus rates and gingivitis) and prosthodontics needs. Cost-effective means of managing the high prevalence of unmet needs should be a priority of public health officials and dental NGO's in the Philippines.

\section{ACKNOWLEDGMENT}

The authors wish to thank the organizers and participants involved in the study which was partly supported by the endowment fund, College of Dentistry, University of Saskatchewan, Canada.

\section{REFERENCES}

1. WHO. World Oral health Report 2003. Continuous improvement in oral health in the 21 st century-the approach of the WHO oral health program. Petersen PK. Oral health program. Non communicable disease prevention and health promotion. Geneva, Switzerland.

2. Singh A, Purohit BM. Dental Public Health! A mistaken identity. Advances in Life Science and its Applications 2012;1(3):58-61.

3. Baker JL. Impacts of financial, food, and fuel crisis on the urban poor. Directions in urban development, Urban Development Unit, World Bank. December 2008. (http:// siteresources.worldbank.org/INTURBANDEVELOPMENT/ Resources/336387-1226422021646/directions_2.pdf?resource urlname $=$ directions_2.pdf)

4. Castro LV. Users' forum on the 2006 poverty statistics for the basic sectors and 2006 child development index. Republic of the Philippines, National Statistical Coordination Board. June 2009. (http://www.nscb.gov.ph/poverty/default.asp).

5. Virola RA. 2009 Official Poverty Statistics. Republic of the Philippines, National Statistical Coordination Board. June 2011. (http://www.nscb.gov.ph/poverty/2009/Presentation_RAVirola. pdf).

6. Gamonal JA, Locker D, Miller Y. Evaluation of subjective oral health status indicators. J Pub Health Dent 1994;54(3):167-176.

7. Sheiham A, Steele JG, Marcenes W, Tsakos G, Finch S, Walls AWG. Prevalence of impacts of dental and oral disorders and their effects on eating among older people; a national survey in Great Britain. Comm Dent Oral Epidemiol 2001;29: 195-203.

8. Musacchio E, Perissinotto E, Binotto P, et al. Tooth loss in the elderly and its association with nutritional status, socioeconomic and lifestyle factors. Acta Odontol Scand 2007;65:78-86.

9. Craddock HL. Consequences of tooth loss. Dental Update 2009;36:616-619.

10. Fiske J, Davis DM, Frances C, Gelbier S. The emotional effects of tooth loss in edentulous people. British Dental Journal 1998; 184(2):90-93.

11. American Association for Dental Research. Review validates association between oral health and heart health: Highlights Need for Further Research April 2012. aadronline.com/files/ public/12AADRPressRelease_AHAStatement.pdff.
12. Uetani M, Jimba M, Kaku T, Ota K, Wakai S. Oral health status of vulnerable groups in a village of the Central Highlands, southern Vietnam. Int J Dent Hyg 2006 May;4(2):72-76.

13. Available at: http://www.ibon.org/ibon_surveys.php

14. Republic of the Philippines, Department of Health. Available at: www.doh.gov.ph/node/1066.html

15. Benzian H, Monse B, Heinrich-Weltzien R, Hobdell M, Mulder J, van Palenstein Helderman W. Untreated severe dental decay: a neglected determinant of low Body Mass Index in 12-year-old Filipino children. BMC Public Health 2011 Jul;13(11):558.

16. 'Total Population by Province, City, Municipality and Barangay: as of May 1, 2010'. 2010 Census of Population and Housing. National Statistics Office. Retrieved 11 November 2013.

17. Machin D, Campbell M, Fayers, P, Pinol A. Sample size tables for clinical studies. 2nd ed. Blackwell Science IBSN 0-86542870-0,1997.p.21-22.

18. Altman DG, Machin D, Bryant TN, Gardner MJ. Statistics with confidence. 2nd ed. BMJ Books ISBN 072791375 1, 2000. p.46-47.

19. World Health Organization. Oral health surveys: Basic methods. 4th ed. Geneva: World Health Organization 1997.

20. Shrout PE, Fleiss JL. Intraclass correlations: Uses in assessing rater reliability. Psychol Bulletin 1979;2:420-428.

21. Garcia ML, Cutress TW. A national survey of periodontal treatment needs of adults in the Philippines. Community Dent Oral Epidemiol 1986;14:313-316.

22. Papapanou PN. Epidemiology of periodontal disease: an update. J Int Acad Periodontol 1999;1:110-116.

23. Petersen PE, Ogawa H. 'Strengthening the prevention of periodontal disease: the WHO approach,' J Periodontol 2005; 76(12):2187-2193.

24. Hessari H, Vehkalahti MM, Eghbal MJ, Murtomaa HT. Oral health among 35 to 44 years old Iranians. Med Princ Pract 2007; $16: 280-285$.

25. Kumar A, Virdi M, Veeresha KL, Bensal V. Oral health status and treatment needs of rural population of Ambala, Haryana, India. Internet J Epidemiol 2010;8(2): DOI: 10.5580/1367.

26. Peeran SW, Ranjith Singh AJA, Alagamuthu G, Naveen Kumar PG. Periodontal status and risk factors among adults of the Sebha city (Libya). Dent Res J (Isfahan) 2013; Jul-Aug;10(4):533-538.

27. Catovic A, Jerolimov V, Catic A. Tooth loss and the condition of the prosthodontics appliances in a group of elderly home residents. J Oral Rehabil 2000;27(3):199-204.

28. Hoover JN, McDermott R. The dental treatment needs of elderly patients seen at a university teaching clinic. American J Dent 1990;3:213-216.

29. Lewis S, Jagger RG, Treasure E. The dental prosthetic status of psychiatric in patients in South Wales. J Disability and Oral Health 2003;4(1):9-14.

30. Jelenković A, Stančić, I, Tihaček-Šojić, L, Živković R, Miličić B. A preliminary evaluation of normative and realistic needs for prosthetic treatment among frail elderly patients in Serbia. J Dent Science 2013;8(1):15-20.

31. Kumar S, Tadakamadla J, Tibdewal H, Prabu D, Kulkarni S. Dental prosthetic status and treatment needs of Green Marble mine laborers, Udaipur, India. Dent Res J 2011;8(3):123-127.

32. Ettinger RL, Beck JD. The new elderly: what can the dental profession expect? Spec Care Dentist 1982;2(2):62-69.

33. Mtaya M, Brudvik P, Åstrøm AN. Prevalence of malocclusion and its relationship with sociodemographic factors, dental caries 
and oral hygiene in 12 to 14-year-old Tanzanian Schoolchildren. Euro J Orth 2009;31(5):467-476.

34. Proffit WR, Fields HW. Contemporary Orthodontics. St. Louis, Mo, USA: Mosby 2007.

35. Kenealy P, Frude N, Shaw W. An evaluation of the psychological and social effects of malocclusion: some implications for dental policy making. Soc Science Med 1989;28(6):583-591.

36. Dhar V, Jain A, Van Dyke TE, Kohli A. Prevalence of gingival diseases, malocclusion and fluorosis in school-going children of rural areas in Udaipur district. J Ind Soc Pedo and Prev Dent 2007;25(2):103-105.

37. Muppa R, Bhupathiraju P, Duddu MK, Dandempally A, Karre DL. Prevalence and determinant factors of malocclusion in population with special needs in South India. J Indian Soc Pedod Prev Dent 2013;31:87-90.

38. Van Palenstein Helderman WH, Benzian H. Implementation of a basic package of oral care: towards a reorientation of dental NGOs and their volunteers. Int Dent J 2006;56(1):44-48.

39. Janet Han S, Quinonez CR. Dental volunteerism: is the current model working? J Can Dent Assoc 2013;79:d69.

\section{ABOUT THE AUTHORS}

\section{Vincent Torresyap (Corresponding Author)}

Assistant Professor, Department of Dentistry, University of Saskatchewan, Saskatchewan, Canada, Phone: 3069665087, e-mail: vincent.torresyap@usask.ca

\section{Jay Hoover}

Professor, Department of Dentistry, College of Dentistry, University of Saskatchewan, Saskatchewan, Canada

\section{Maria Torresyap}

Instructor, Department of Dentistry, College of Dentistry, University of Saskatchewan, Saskatchewan, Canada

\section{Chandima Karunanayake}

Biostatistician, Department of Canadian Centre for Health and Safety in Agriculture, University of Saskatchewan, Saskatchewan, Canada 